\title{
Importance Rating Likert Scale
}

National Cancer Institute

\section{Source}

National Cancer Institute. Importance Rating Likert Scale. NCI Thesaurus. Code C125542.

A scale for the subjective scoring of importance that ranges from 0: Not at all important to 4: Extremely important. 